\title{
GESTÃO DO LIXO ELETRONICO A PARTIR DA VISÃO TEÓRICA DA ECONOMIA CICLICA NO PONTAL DO PARANAPANEMA.
}

\author{
MANAGEMENT OF GARBAGE ELETRONICO THE THEORETICAL VISION FROM CYCLIC \\ ECONOMY IN PONTAL DO PARANAPANEMA .
}

\author{
GESTIÓN DE BASURA ELETRONICO LA VISIÓN TEÓRICA DE CÍCLICA ECONOMÍA EN \\ PONTAL DO PARANAPANEMA .
}

Juliene Maldonado Orosco de Andrade

Mestranda em Meio Ambiente e Desenvolvimento Regional, UNOESTE, Brasil julieneorosco@hotmail.com

\section{INTRODUÇ̃̃o}

Na natureza nada se cria, nada se perde e tudo se transforma, segundo Antonie Lavosier (1794). Os organismos naturais nascem para morrer, e seus resíduos são transformados em energia para outras espécies, formando um processo circular em perfeito equilíbrio, delineando a inteligência do planeta. Por outro lado o homem vem causando desequilíbrio e, em longo prazo a natureza não irá mais suportar. Vários estudiosos colocam que a economia circular poderia minimizar os impactos humanos no meio ambiente. O sistema de economia circular é baseado na inteligência da natureza, onde os resíduos são insumos para novos produtos. Logo, a economia circular é a ciência que cabe repensar muito além das práticas da economia em "reduzir, reutilizar e reciclar", ao passo que a tecnologia e a modernidade vêm crescendo, mas como uma forma sustentável. Desenvolvemos a economia de forma linear, do qual, subtraímos a matéria prima da natureza e produzimos consequentemente um grande acúmulo de resíduos. Segundo Michael Braungart e William McDonough (2002):

[...] adotamos um modelo de produção linear, baseado em "extrair fabricar - utilizar - descartar" (e às vezes reciclar ou incinerar). Mas jogar "fora" é jogar "dentro". Somos a única espécie do planeta que gera lixo, algo que é inútil e tóxico. 
Contudo à obsolescência programada, que se trata do consumo por tecnologia sempre de última geração, mais modernas, causa um descarte exorbitante de resíduos sólidos como: eletrodoméstico, eletro portáteis, acessórios de informática e telefonia, e chegando ao fim de sua vida útil, esses produtos são denominados "resíduos de equipamentos eletroeletrônicos" (REEE). Neste quadro apresentamos a divisão dos itens eletroeletrônicos.

\section{Quadro 01 - Categorias de Equipamentos Eletroeletrônicos}

\begin{tabular}{|c|c|}
\hline Categoria dos REEE & Lista de Produtos \\
\hline Eletrodomésticos Grandes & $\begin{array}{l}\text { Grandes aparelhos de refrigeração; refrigeradores; freezers; máquinas de lavar e } \\
\text { secar roupa; máquinas de lavar louça; fogões e chapas elétricas; micro-ondas; } \\
\text { aparelhos de aquecimento elétrico; radiadores elétricos, ventiladores elétricos, } \\
\text { aparelhos de ar condicionado; Exaustores. }\end{array}$ \\
\hline $\begin{array}{l}\text { Eletrodomésticos } \\
\text { Pequenos }\end{array}$ & $\begin{array}{l}\text { Aspiradores de pó; varredores de tapete; máquinas de costura e tecelagem e outras } \\
\text { máquinas para produtos têxteis; ferros elétricos e outros aparelhos para tratar o } \\
\text { vestuário; torradeiras, fritadeiras, moinhos, máquinas de café e aparelhos para abrir } \\
\text { ou fechar recipientes ou embalagens; facas elétricas, máquinas de cortar cabelo, } \\
\text { secadores de cabelo, escovas de dente elétricas, aparelhos de barbear; relógios. }\end{array}$ \\
\hline $\begin{array}{l}\text { Equipamentos de } \\
\text { Tecnologia da Informação } \\
\text { e Telecomunicações }\end{array}$ & $\begin{array}{l}\text { Mainframes; minicomputadores, impressoras, computadores pessoais (CPU, mouse, } \\
\text { tela e teclado incluídos), laptops, notebook, notepad, impressoras, equipamentos de } \\
\text { fotocópia; máquinas de escrever elétricas e eletrônicas; calculadoras; terminais de } \\
\text { usuário e sistemas; fac-símile; telex; telefones, telefones celulares, sistemas de } \\
\text { atendimento automático. }\end{array}$ \\
\hline $\begin{array}{l}\text { Equipamentos de } \\
\text { Entretenimento }\end{array}$ & $\begin{array}{l}\text { Aparelhos de rádio, TV; câmeras de vídeo; gravadores de vídeo; gravadores hi-fi; } \\
\text { amplificadores de áudio, instrumentos musicais; outros produtos ou equipamentos } \\
\text { para fins de registro ou de reprodução de som ou imagem. }\end{array}$ \\
\hline $\begin{array}{l}\text { Equipamentos de } \\
\text { Iluminação }\end{array}$ & $\begin{array}{l}\text { Luminárias para lâmpadas fluorescentes, com exceção dos aparelhos de iluminação } \\
\text { doméstica; lâmpadas fluorescentes; lâmpadas fluorescentes compactas; lâmpadas } \\
\text { de alta intensidade de descarga, incluindo lâmpadas de sódio sob pressão, de } \\
\text { iodetos, de sódio de baixa pressão, iluminação ou equipamento com a finalidade de } \\
\text { difundir ou controlar a luz, com exceção das lâmpadas de incandescência. }\end{array}$ \\
\hline $\begin{array}{l}\text { Ferramentas Elétricas e } \\
\text { Eletrônicas (com exceção } \\
\text { das ferramentas de grande } \\
\text { escala industrial) }\end{array}$ & $\begin{array}{l}\text { Brocas; serras, máquinas de costura, equipamentos para tornear, lixar, triturar, } \\
\text { serrar, cortar, tosar, brocar, fazer furos, puncionar, dobrar, encurvar, ou } \\
\text { semelhantes, ferramentas para rebitar, pregar ou aparafusar; ferramentas para solda; } \\
\text { equipamentos para pulverizar, espalhar; ferramentas para cortar arbustos. }\end{array}$ \\
\hline $\begin{array}{c}\text { Brinquedos e } \\
\text { Equipamentos Esportivos }\end{array}$ & $\begin{array}{l}\text { Trens elétricos ou carros de corrida, consoles de vídeo game, vídeo game, bicicletas } \\
\text { ergométricas; equipamento desportivo com componentes elétricos ou eletrônicos. }\end{array}$ \\
\hline Equipamentos Médicos & $\begin{array}{l}\text { Equipamentos de radioterapia; cardiologia; diálise; ventiladores pulmonares, } \\
\text { equipamentos de medicina nuclear, equipamentos de laboratório para diagnóstico in } \\
\text { vitro; analisadores; freezers; testes de fertilização. }\end{array}$ \\
\hline $\begin{array}{l}\text { Instrumentos de } \\
\text { Monitoramento }\end{array}$ & $\begin{array}{l}\text { Detectores de fumaça; reguladores de aquecimento; termostatos; aparelhos de } \\
\text { medição, pesagem ou regulação, monitoramento e outros instrumentos de controle. }\end{array}$ \\
\hline $\begin{array}{l}\text { Distribuidores } \\
\text { Automáticos }\end{array}$ & $\begin{array}{l}\text { Distribuidores automáticos de bebidas e garrafas, de produtos sólidos, de dinheiro e } \\
\text { todos os demais aparelhos que forneçam automaticamente qualquer produto. }\end{array}$ \\
\hline
\end{tabular}

Fonte: Adaptado de Diretiva Europeia de REEE. (UNIÃO EUROPEIA, 2002)

A justificativa desta pesquisa se atenta a fato de que esses produtos não são biodegradáveis, contém plástico, alumínio, vidro, ferro e cobre, apresenta também elementos tóxico-químicos. A figura abaixo ilustra essa divisão: 
Figura 01 - Frações Típicas de Materiais Presentes em REEE

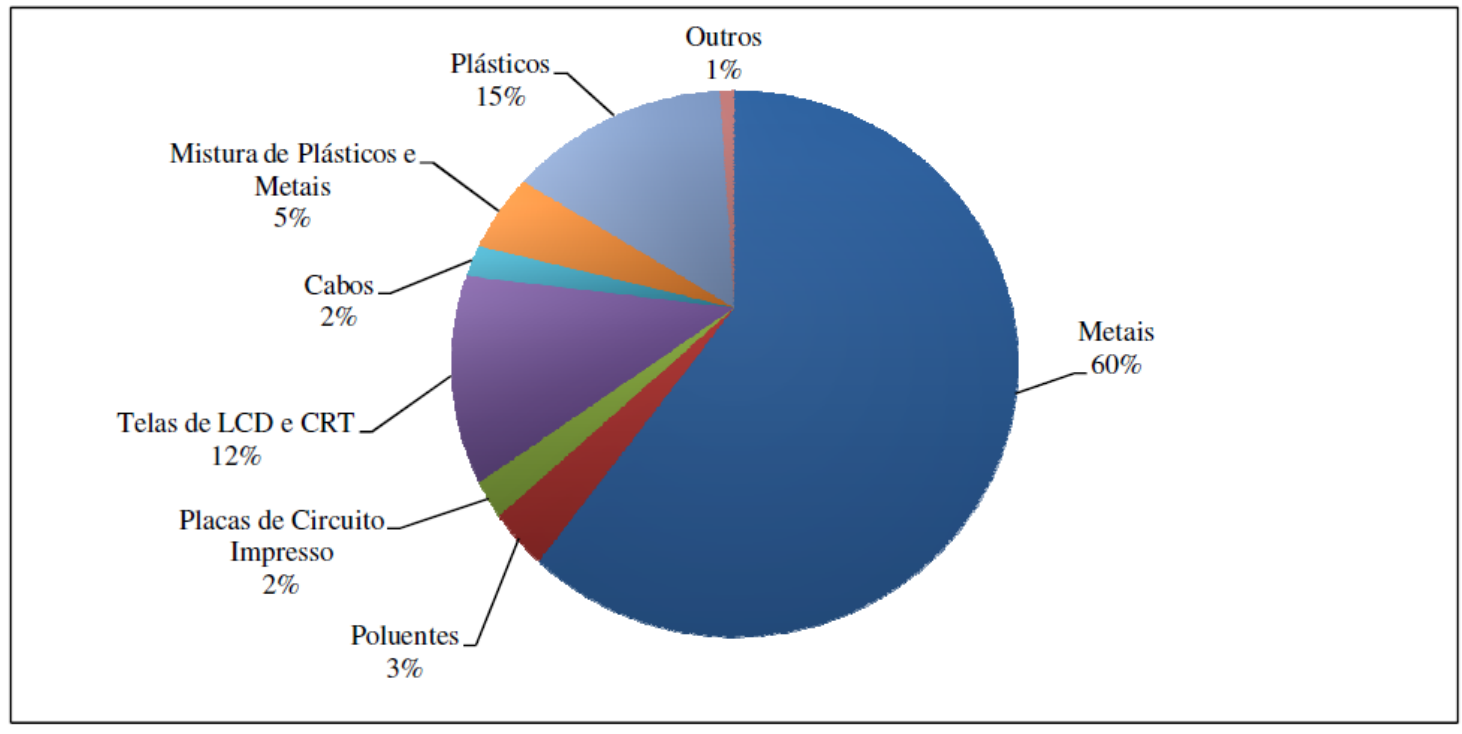

Fonte: Adaptado de Widmer et al. (2005)

O descarte incorreto em aterros e lixões pode provocar uma série de impactos ambientais, tanto no solo como na água. Diversos países possuem leis, e normas, que regulamentam os REEE. No Brasil através do Ministério do Meio Ambiente, por meio da Politica Nacional de Resíduos Sólidos (PNRS) lei no 12.305/10,

[...] prevê a redução na geração de resíduos, tendo como proposta a prática de hábitos de consumo sustentável e um conjunto de instrumentos para propiciar o aumento da reciclagem e da reutilização dos resíduos sólidos (aquilo que tem valor econômico e pode ser reciclado ou reaproveitado) e a destinação ambientalmente adequada dos rejeitos (aquilo que não pode ser reciclado ou reutilizado).

De acordo com Leite (2010a), a aprovação da PNRS preconiza grandes oportunidades de negócios empresariais para todos os prestadores de serviços de Logística Reversa.

Entretanto, sabemos que a implementação de regras para a logística reversa não é uma tarefa que envolva somente empresas, é necessários que pessoas identifiquem o seu papel neste novo modelo, para isso iremos analisar a Região do Pontal do Paranapanema, se trata de uma região com 18844,60 km², que compreende 32 municípios do estado de São Paulo. Está localizada no extremo oeste do estado de São Paulo, na região sudeste do Brasil, em uma posição estratégica considerando tanto sua proximidade com os estados de Mato Grosso do Sul e Paraná quanto o advento do Mercosul e que segunda dados coletados no ultimo Mutirão do Lixo Eletrônico (2015), foram arrecadados mais de 70 tonelada/ano. A ideia é estudar a viabilidade econômica na utilização dos resíduos eletro eletrônicos. Esperamos como resultados da pesquisa propor a gestão para os resíduos eletrônicos na região, através economia circular economicamente oportuna no meio ambiente brasileiro. 


\section{OBJETIVOS}

O objetivo geral deste projeto é propor a gestão dos resíduos de lixo eletrônico, como forma de geração de renda sustentável, no Pontal do Paranapanema, por meio da teoria de economia cíclica.

Para isso os objetivos específicos serão:

1) Estudar o aspectos da Economia Cíclica, como forma sustentável de uma economia restaurativa e regenerativa.

2) Pesquisar o atual cenários nacional e internacional quanto o processo de reuso de materiais do lixo eletrônico.

3) Analisar o potencial do Pontal do Paranapanema, para desenvolvimento e amparo quanto à gestão do lixo eletrônico.

4) Propor formas de gestão dos resíduos eletrônico baseado na economia cíclica.

\section{HIPÓTESES / RESULTADOS}

Verificada a viabilidade econômica, propor através de desafios e oportunidades o desenvolvimento da gestão do resíduo eletrônico no Pontal do Paranapanema. Produzir mais e com menos impactos ambientais.

\section{METODOLOGIA}

Para o desenvolvimento deste projeto optou-se realizar um levantamento bibliográfico sobre a temática abordada, que de acordo com Ruiz (1996, p.58), "a pesquisa bibliográfica consiste no exame do manancial teórico, para levantamento e análise do que já se produziu sobre determinado assunto que se tem como tema de pesquisa científica". Para Lakatos e Marconi (2002, p.225) referem-se às revisões bibliográficas como: "a citação das principais conclusões a que outros chegaram permitir salientar a contribuição da pesquisa realizada, demonstrar contradições ou reafirmar comportamentos e atitudes". De acordo com Santos (2001, p.26), este tipo de pesquisa é tipicamente a primeira aproximação de um tema e visa criar maior familiaridade em relação a um fato ou fenômeno. Quase sempre feita como levantamento bibliográfico, entrevistas com profissionais que estudam/atuam na área.

\section{CONCLUSÃO}

A presente pesquisa se trata de um pré-projeto, que está em fase inicial de pesquisas porém, visa analisar a viabilidade econômica, na utilização de resíduos eletro eletrônico, sob o conceito da economia circular em eliminar resíduos. A mudança será possível através do empreendedorismo.

Com a tendência mundial de preservação ambiental, o empreendedor deverá inserir-se nesse mercado visando à valorização do meio ambiente, respeitando as leis que regulamentam esse 
setor, transformando o processo de reciclagem em uma atividade rentável econômica e financeiramente, aproveitando o grande apelo popular de praticamente todas as nações mundiais. Assim o empreendedor deverá vincular sua empresa às oportunidades requeridas pela sociedade como um todo, ou seja, o empreendimento deverá estar inserido no conceito de despoluição e descontaminação ambiental por meio da reciclagem de produtos, que até então, eram descartados em lixo comum ou mesmo em aterros sanitários. Criando desta forma uma empresa com fins lucrativos, mas com forte apelo sócio ambiental. Para concluir, uma frase do pai da administração Peter Druker diz que "a melhor forma de prever o futuro é cria-lo".

\section{AGRADECIMENTO}

Agradeço primeiramente a Deus pela vida, a minha família que nunca mede esforçar para que eu atinja meus objetivos. Agradeço a Universidade por proporcionar a oportunidade de ingressar novamente no aprofundamento de estudo e se deparar com o desconhecido e incentivar a buscar o novo podendo ampliar meus conhecimentos de vida.

\section{REFERÊNCIAS BIBLIOGRÁFICAS}

BRAUNGART, M.; McDonough, W. Cradle to cradle - criar e reciclar ilimitadamente. Editora GG Brasil, 2008, p.192.

BRASIL. Lei no. 12.305, de 02 de agosto de 2010. Dispõe sobre a Política Nacional dos Resíduos Sólidos. Disponível em: Acesso em: 06 de abril/2016.

CAVALAZZI, Eugênio; VALNTE, Luciana. Logística reversa: muito além da reciclagem. 09 fevereiro 2010. Disponível em: http://www.logisticadescomplicada.com/logistica-reversa-muito-alem-da-r reciclagem/. Acesso em: maio/2012.

Cradle to cradle: Disponível em: < https://www.youtube.com/watch?v=ij3Elbc6otQ > Acesso em: abr.2016.

Economia Cíclica. Disponível em: < https://www.youtube.com/watch?v=zhFhgXb4hO4> Acesso em: abr.2016

LAKATOS, Eva V.; MARCONI, Marina A. Técnicas de Pesquisa. 5. ed. São Paulo: Atlas, 2002.

Mutirão do Lixo Eletrônico. Disponível em: <http://mutiraodolixoeletronico.sp.gov.br/site/default.aspx. >. Acesso em: 11 abr.2016.

Obsolescência Programada. Disponível em: <https://www.youtube.com/watch?v=VkPScfQG-Y8>>. Acesso em abr. 2016 
ONU e IBGE divulgam relatórios de população 2002. Brasil. Rio de Janeiro: IBGE, Disponível em: <http://www.ibge.gov.br/home/presidencia/noticias/03122002relatorio_onu.shtm>. Acesso em: abr.2016.

Puma: Disponível em: < https://www.youtube.com/watch?v=pVIGn6V4Gbw> Acesso em: abr.2016.

RODRIGUES, Alan. Economia e Negócio: O negócio bilionário do lixo eletrônico. Revista Isto é, São Paulo, a.15, n. 2376, Abr.2016. Disponível em: <http://www.istoe.com.br/assuntos/6_ECONOMIA+NEGOCIOS>. Acesso em: 13 abr. 2016.

SANTOS, Antônio Raimundo dos. Metodologia Científica: a construção do conhecimento. 4 ed. Rio de Janeiro: DP\&A editora, 2001.

UNIVERSIDADE DO OESTE PAULISTA. Assessoria de Imprensa UNOESTE. 8o Mutirão do Lixo Eletrônico arrecada 70 t de materiais. 13 de jun./2015. Disponível em: . Acesso em: 02 abril, 2016.

WIDMER, R.; OSWALD-KRAPF, H.; SINHA-KHETRIWAL, D.; SCHNELLMAN, M.; BÖNI, H. Global perspectives on e-waste. Environmental Impact Assessment Review, v.25, p. 436-458, 2005.

TOWNSEND, T. G. Environmental issues and management strategies for waste electronic and electrical equipment. Journal of the Air and Waste Management Association. v. 61, n.6, p. 587-610, 2011. 